\title{
LECTURES ON STATISTICS.
}

The following is the Syllabus of a course of five lectures delivered during the current session before the members of the Institute, at Staple Inn Hall, by Miss Ethel M. Elderton, Research Fellow, University College, London:

\section{SOME PRACTICAL EXAMPLES OF STATISTICAL WORK} WITH SPECIAL REFERENCE TO CORRELATION.

1. Explanation of terms ; collection of data, \&c. ; graphic work.

2. Means and standard deviations and their numerical calculation and why they are wanted in measuring correlation.

3. Simplest method of calculating correlation.

4. Regression and the product-moment method.

5. Interpretation of results and discussion of various points that arise.

\section{Qbituary.}

Harry Watson, Student of the Institute, and Lieutenant, King's Liverpool Regiment.

Killed in Action 12 August 1916.

Arthur Vernon Clare, Probationer of the Institute, 2nd Lieutenant, 1/21 Battalion London Regiment.

Killed in Action 15 September 1916. 